\title{
Controlling Osteogenic Differentiation through Nanoporous Alumina
}

\author{
Shiuli Pujari-Palmer1, Thomas Lind2, Wei Xia1, Liping Tang3, Marjam Karlsson Ott1 ${ }^{*}$ \\ ${ }^{1}$ Applied Material Science, Department of Engineering Sciences, The Ångström Laboratory, Uppsala University, \\ Uppsala, Sweden \\ ${ }^{2}$ Department of Medical Sciences, Uppsala University, Uppsala, Sweden \\ ${ }^{3}$ Bioengineering Department, University of Texas at Arlington, Arlington, USA \\ Email: ${ }^{*}$ marjam.ott@angstrom.uu.se
}

Received 7 December 2013; revised 6 March 2014; accepted 20 March 2014

Copyright (C) 2014 by authors and Scientific Research Publishing Inc.

This work is licensed under the Creative Commons Attribution International License (CC BY).

http://creativecommons.org/licenses/by/4.0/

(c) (i) Open Access

\begin{abstract}
Nanotopographical features are found to have significant effects on bone behavior. In the present study, nanoporous aluminas with different pore sizes $(20,100$ and $200 \mathrm{~nm}$ in diameter), were evaluated for their osteoinductive and drug eluting properties. W20-17 marrow stromal cells were seeded on nanoporous alumina with and without the addition of BMP-2. Although cell proliferation was not affected by pore size, osteogenic differentiation was $200 \mathbf{~ n m}$ as compared to 20 and $100 \mathrm{~nm}$ pores induced higher alkaline phosphatase activity (ALP) and osteocalcin expression levels, thus indicating osteoblastic differentiation. Cell morphology revealed that cells cultured on $20 \mathrm{~nm}$ pores adopted a rounded shape, while larger pores $(200 \mathrm{~nm})$ elicited an elongated morphology. Furthermore, ALP expression levels were consistently higher on BMP-2 loaded nanoporous alumina surfaces compared to unloaded surfaces, indicating that not only is nanoporous alumina osteoinductive, but also has the potential to be used as a drug eluting bone-implant coating.
\end{abstract}

\section{Keywords}

Nanotopography; Nanoporous Alumina; Osteogenic Differentiation; Marrow Stromal Cells

\section{Introduction}

Bone diseases and injuries such as osteosarcoma, osteoporosis, and bone fractures are a major clinical and socioeconomic impetus for the development of new bone replacement strategies [1]. The interdisciplinary research in bone tissue engineering has made some successes on the development of bone scaffolds to accelerate bone

*Corresponding author.

How to cite this paper: Pujari-Palmer, S., Lind, T., Xia, W., Tang, L.P., Ott, M.K. (2014) ontrolling Osteogenic Differentiation through Nanoporous Alumina. Journal of Biomaterials and Nanobiotechnology, 5, 98-104.

http://dx.doi.org/10.4236/jbnb.2014.52012 
regeneration [2]. Current research has focused on the creation of highly porous, three dimensional, scaffolds that can be loaded with specific tissue inducing factors to promote tissue regeneration [3]-[5]. It is believed that the surface properties of the surrounding microenvironment, such as surface roughness, elastic modulus, chemical reactivity, wettability, nanoscale features (pores, pillars, pits, etc.), have a significant influence on the stem cell responses, including cell proliferation and differentiation [6]. Studies have suggested that scaffold pore size and geometry can affect stem cell differentiation. For example, some have observed that pores ranging from 70 - 100 $\mathrm{nm}$ facilitate osteoblast differentiation via increased stem cell elongation, and by inducing cytoskeletal stress [7]. In contrast, others reported that a smaller pore size, between 20 - $30 \mathrm{~nm}$, enhanced osteogenic differentiation with increased focal adhesions [8]. The purpose of this study was to identify pore size ranges that affect stem cell proliferation and subsequent osteogenic differentiation. To determine the critical pore sizes for cell osteogenic responses, we used nanoporous alumina as a model substrate. Nanoporous alumina is created by anodic oxidation of aluminium (anodization) in polyprotic acids, producing a well-ordered structure of nanopores. Moreover, nanoporous alumina has shown promising potential to be implemented as a bone implant coating [9], immunoisolation device [10], and for drug delivery applications [11]-[14]. It should be noted that human osteoblasts cultured on nanoporous alumina maintain a physiological phenotype [9] [15].

The aim of this study was to investigate the effect of nanotopography on cell behavior. A murine bone marrow stromal cell line, W20-17, was used to investigate the potential of nanoporous alumina as an inductive substrate for osteogenic differentiation. We investigated the effect of nanotopography on osteogenic differentiation on varied pore sizes (20, 100 and $200 \mathrm{~nm}$ in diameter). The efficacy of nanoporous alumina to release an osteoconductive agent-bone morphogenic protein-2 (BMP-2) was also investigated. Cell proliferation, osteogenic differentiation assays, and gene expression levels were performed in vitro. Cell morphology was analyzed with scanning electron microscopy [16].

\section{Materials and Methods}

Nanoporous alumina membranes with pore diameters of 20, 100, and $200 \mathrm{~nm}$ (Anodisc Whatman International Ltd., Madison, England) were utilized in this study. The membrane discs were $13 \mathrm{~mm}$ in diameter and $60 \mu \mathrm{m}$ thick. The membranes have similar surface roughness and surface chemistry, independent of porosity [17]. For detailed chemical compositions of the nanoporous alumina membranes, please refer back to the studies done by Karlsson et al. [17].

\subsection{Loading Nanoporous Alumina Surfaces with BMP-2}

Each membrane was soaked overnight in a $40 \mu \mathrm{l}$ solution of BMP-2, at a concentration of $200 \mathrm{ng} / \mathrm{ml}$ at $4^{\circ} \mathrm{C}$. The impregnated surfaces serve as a slow release reservoir of BMP-2.

\subsection{Cell Culture and Morphological Examination}

Stem cells (W20-17, mouse bone marrow stromal cells, European Collection of Cell Cultures) were maintained in DMEM/F12 culture medium supplemented with 10\% fetal bovine serum (Hyclone), $2 \mathrm{mM}$ glutamine, 100 $\mathrm{U} / \mathrm{mL}$ penicillin, and $100 \mu \mathrm{g} / \mathrm{mL}$ streptomycin (Sigma Aldrich, Germany). Cells were expanded in $75 \mathrm{~cm}^{2}$ flasks at $37^{\circ} \mathrm{C}$, in a humidified atmosphere with $5 \% \mathrm{CO}_{2}$. Using 24 well plates, cells were seeded on nanoporous alumina membranes as well as control wells (tissue culture polystyrene, TCPS) at a concentration of $5000 \mathrm{cells} / \mathrm{cm}^{2}$. After 2 days of incubation, cells were fixed in $2.5 \%$ glutaraldehyde. The samples were then dehydrated through a series of alcohol concentrations (10\%, 30\%, 50\%, 70\%, 90\%, and 99\%). Hexamethyl dixilazane was used in the final dehydration step, followed by air-drying. The samples were then coated with Au/Pd for examination using a Scanning Electron Microscope (AS02 SEM / EDS 1550, Zeiss).

\subsection{Cell Proliferation and Differentiation}

For the cell proliferation study, W20-17 cells were seeded on nanoporous alumina membranes as well as control wells in 24 well plates at a density of 5000 cells $/ \mathrm{cm}^{2}$. After incubation for different periods of time (2 and 7 days), cell proliferation was evaluated with the AlamarBlue assay (Invitrogen) using the manufacturers' instructions. Cell proliferation rate was determined by calculating the percentage of cell number that increased by time. To quantify ALP activity, Alkaline Phosphatase Substrate System (Sigma Aldrich, Sweden) was used, according 
to the manufactures' instructions. ALP values were then normalized to total intracellular protein content by using the Micro Bicinchoninic Acid (Micro BCA, Pierce, USA) assay kit. Osteocalcin (OC) gene expression levels were determined by using qPCR and normalized to beta-actin [18].

\subsection{Statistical Analysis}

Ordinary ANOVA was performed using standard methods for Scheffe's multiple comparison test. $P<0.05$ was chosen as significant.

\section{Results}

\subsection{Cell Morphology and Viability}

It is well established that stem cells change morphology as part of the differentiation processes. Interestingly, we have observed that cells present different morphology depending on nanoporosity. Cell morphology was analyzed after 2 days in culture using SEM. The images of cells cultured on $20 \mathrm{~nm}$ membranes showed somewhat flat and round-shaped cells as compared to the $200 \mathrm{~nm}$ membranes (Figure 1(c)). On this surface, cells adopted a far more elongated form, indicative of preosteoblastic morphology (Figure 1(c)). Cells grown on $100 \mathrm{~nm}$ membranes had similar morphology as cells on the $200 \mathrm{~nm}$ membranes. Images of these cells are, therefore, not shown. In general, higher cell numbers were found on the polystyrene surface as compared to the nanoporous alumina surfaces (Figure 1(a)). There was however no significant difference in cell number among the membranes $(20,100,200 \mathrm{~nm})$ with cells grown without the presence of BMP-2. Proliferation rate was determined by analyzing the increase in cell number from day 2 to day 7 . Although the cells initially adhered to the TCPS surfaces in higher amounts, no difference in proliferation rate was seen between the TCPS and the alumina membranes (Figure 1(b)). In addition, no significant increase of total cell number and proliferation rate was seen with the addition of BMP-2.

\subsection{Cell Differentiation}

To directly assess the influence of surface pore size on osteogenic differentiation, we measured the expression of ALP in W20-17 cells. On day 14, we found substantially higher ALP activity in cells adhered to the $200 \mathrm{~nm}$ membrane as compared to the 20 and $100 \mathrm{~nm}$ membranes (Figure 2(a)). The differentiation rate was determined in the same way as proliferation rate. More specifically, ALP was determined by analyzing the increase in enzyme activity from day 2 to day 14. Cells cultured on the $200 \mathrm{~nm}$ membrane also had a higher differentiation rate and osteocalcin (OC) expression level as compared to the $20 \mathrm{~nm}$ membranes, further suggesting that larger diameter nano-topographical features exhibit sustained differentiation towards an osteoblastic lineage (Figure 2(b), Figure 2(c)). Taken together, these results therefore support that the $200 \mathrm{~nm}$ pore size membrane corresponds with an increase in osteogenic activity. The same trend can also be seen in samples exposed to loaded BMP-2 alumina membranes. The addition of BMP-2 increased the overall levels of ALP activity and OC expression as compared to cells without exposure to BMP-2 (Figure 2(a) and Figure 2(c)). However, the differentiation rate of cells with the addition of BMP-2 was the same on all pore sized membranes, showing that BMP-2 enhanced the overall levels of osteogenic differentiation, but was not affected by pore size.

\section{Discussion and Conclusion}

The motivation for incorporating nanofeatures into biomaterials designed for bone implants is physiologically driven. Controlled nanoarchitectural surface features that closely mimic that of native bone morphology, could help promote osteoblast functionality, thereby enhancing overall osseointegration between the implant and tissue interface. In the current study, we have demonstrated that controlled nanoscale features can aid in guiding stromal cells towards osteogenic behavior.

Pore size directly affects cell response in many different ways. We observed that cell proliferation was reduced on nanoporous substrates as compared to TCPS. Pore size also influenced the osteogenic differentiation, with larger pores inducing significantly greater ALP activity and OC expression. During stem cell differentiation, the resulting cell fate depends upon the geometric cues of the substrate surface. When grown on $20 \mathrm{~nm}$ alumina, we see that cells take on a rounded morphology, while cells cultured on $200 \mathrm{~nm}$ alumina adopt a more elongated morphology. Larger diameter pore sizes force cells to stretch to attach to protein aggregates formed on the sub- 


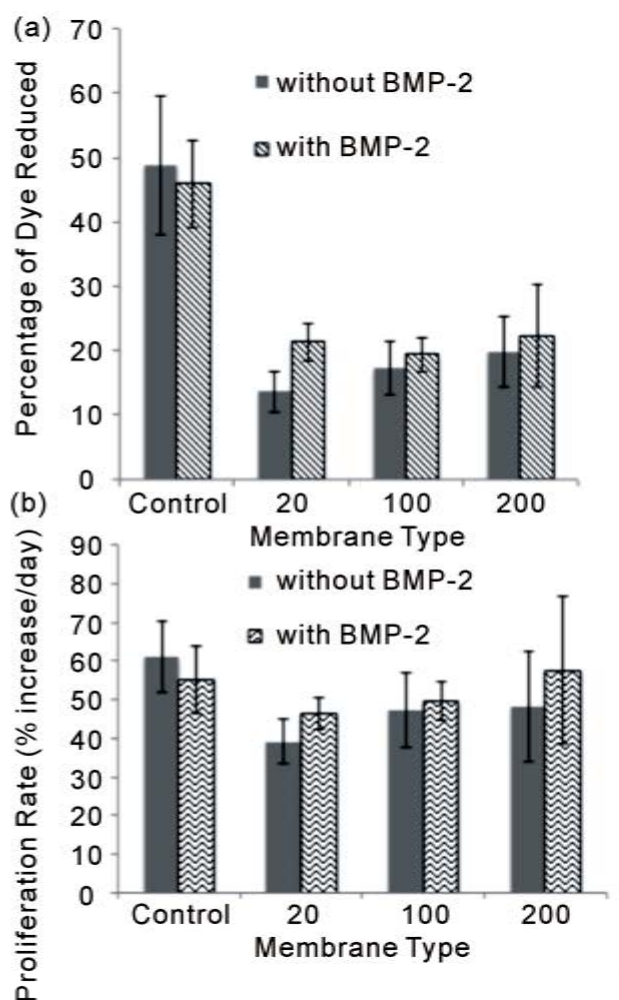

(c)

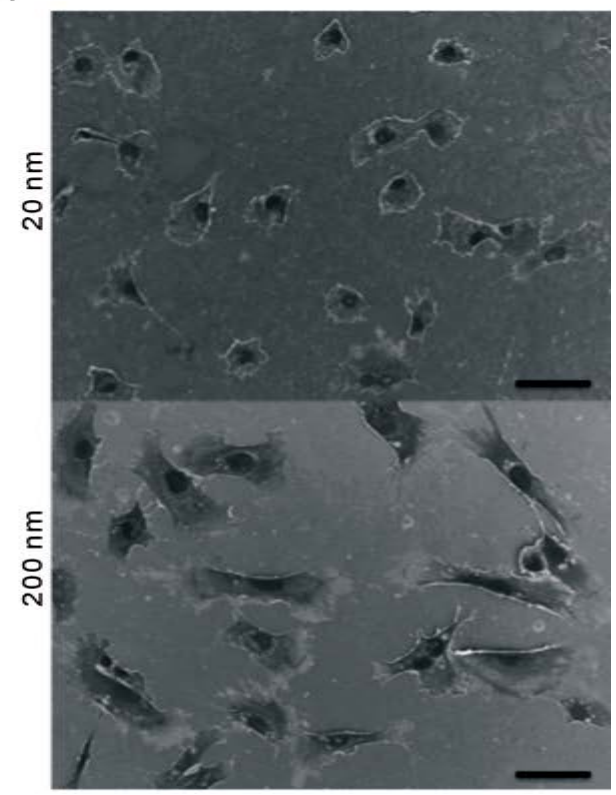

Figure 1. (a) Cell Proliferation: Cell proliferation was analyzed at 7 days, using Alamar Blue. Proliferation was higher on control surfaces compared to nanoporous surfaces. There was no significant difference in cell number among the different pores. (b) Cell Proliferation Rate: Proliferation rate was determined by analyzing the increase in cell number from 2 days to 7 days. Proliferation rate was not significantly different between alumina samples and controls, during the first 7 days of culture. (c) Cell morphology: W20-17 cells cultured for 2 days on $20 \mathrm{~nm}$ nanoporous alumina adopted a round-shaped morphology while cells cultured on $200 \mathrm{~nm}$ nanoporous alumina conformed to a more elongated morphology, indicating that a larger diameter pore size enhances cell spreading. The scale bar represents $20 \mu \mathrm{m}$.

strate surface [19]. This stretching can mimic the topographical guidance towards osteoblast differentiation provided by the native ECM [6]. It is commonly known that when stem and stromal cells are stressed, they can differentiate into a specific lineage that will accommodate the stress in the case of osteoblast differentiation [20]. Finally, some studies have reported that extracellular matrix components [19] are sufficient to stimulate differentiation. The native ECM is a nanoscale environment which facilitates the transfer of information from the extracellular environment, to and from the cell [16] [21]. The topography created on nanoporous alumina could potentially be fabricated to mimic features of the ECM and, thus stimulating integrin receptor activation.

The effective osteogenic agent, BMP-2, is short lived in culture. Drug release from a reservoir is, therefore, an attractive alternative to bulk addition in media [22]. We assessed the efficacy of nanoporous alumina as a drug delivery material by comparing the morphological and biochemical effects of two groups: control and BMP-2 loaded nanoporous alumina membranes. We observed a significant increase in ALP activity and OC expression with the addition of BMP-2. BMP-2 enhanced the magnitude, but not the rate of differentiation. BMP receptors stimulate membrane bound serine and threonine protein kinases, initializing phosphorylation of downstream effector proteins of receptor-regulated Smads (R-Smads) to enhance osteogenic gene transcription. In previous studies, mesenchymal stem cell (MSC) adhesion to BMP2-conjugated $\mathrm{TiO}_{2}$ nanotubes, was found to initiate the dimerization of serine/threonine kinases [23]. This study explores the possibility of using a nanoporous alumina based delivery method to enhance osteogenic differentiation. Perhaps the most significant result, with respect to nanoporous alumina as a drug delivery vehicle, is that ALP activity increased throughout the 14 day culture period. W20-17 stem cells are genetically altered stem cells used to evaluate the bioactivity of BMP-2 through the production of ALP [24], thus being used as an indirect way of detecting BMP-2 activity levels in culture. As 

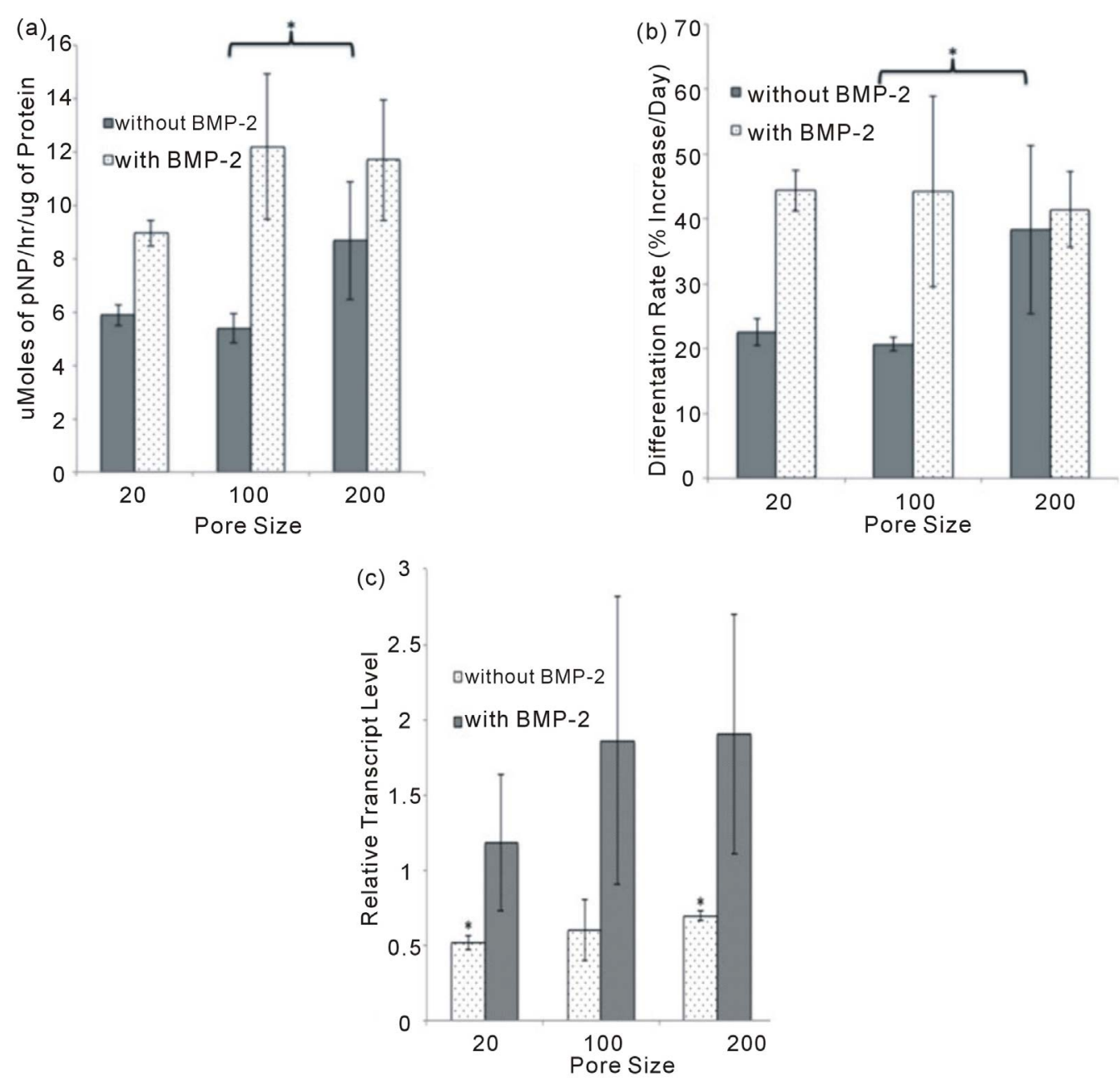

Figure 2. (a) Cell differentiation: Alkaline phosphatase (ALP) activity of polystyrene (control) and nanoporous alumina surfaces (20-, 100-, 200-nm) with and without the addition of BMP-2 was measured after 14 days of culture. Total ALP values were normalized with intracellular protein content. Results indicate higher levels of ALP activity on $200 \mathrm{~nm}$ surfaces compared to $100 \mathrm{~nm}$ and control surfaces by 14 days of culture $(\mathrm{n}=3, \mathrm{p}<0.05)$. A strong trend was found by day 14 with samples cultured with BMP-2, indicating higher levels of ALP activity with an increase in pore size as compared to the control. (b) Cell Differentiation Rate: Cell differentiation rate was determined by analyzing the increase of ALP enzyme activity by time (12 days) from day 2 to day 14 . Results indicate increased differentiation rate on $200 \mathrm{~nm}$ surfaces compared to $100 \mathrm{~nm}$ surfaces ( $\mathrm{p}<0.05)$ on substrates without addition of BMP-2. Differentiation rate seemed to be leveled between all 3 surfaces, with the addition of BMP-2. (c) Gene Expression: OC gene expression with and without BMP-2 was analyzed at 14 days. Results indicate higher levels of OC gene expression on the $200 \mathrm{~nm}$ surfaces compared to $20 \mathrm{~nm}$ surfaces (p< 0.05). The same trend can be seen with cells exposed to BMP-2.

seen in Figure 2(b), ALP levels on all pore sized membranes incorporated with BMP-2 increase with time. A proof of principle of BMP-2 release from the alumina membranes has therefore been shown for the first time.

Alumina nanotopography has a profound effect on stem cell behavior in terms of cell proliferation, morphology, and differentiation, in the presence and absence of BMP-2. This research demonstrates that stem cells can be guided towards an osteogenic fate through selectively manipulating the dimensions of pore size diameter on nanoporous alumina. In addition, our data suggests that nanoporous alumina could be used as a potential vehicle for drug delivery.

\section{Acknowledgements}

This work was funded by Ollie och Elof Ericssons Stifelse för vetenskaplig forskning, Stiftelsen Lars Hiertas 
Minne and STINT (Stiftelsen för internationalisering av högre utbildning och forskning).

\section{References}

[1] Rose, F.R.A.J. and Oreffo, R.O.C. (2002) Bone Tissue Engineering: Hope vs Hype. Biochemical and Biophysical Research Communications, 1, 1-7. http://dx.doi.org/10.1006/bbrc.2002.6519

[2] Seong, J.M., Kim, B.C., Park, J.H., Kwon, I.K., Mantalaris, A. and Hwang, Y.S. (2010) Stem Cells in Bone Tissue Engineering. Biomedical Materials, 6, 2010.

[3] Langer, R. and Vacanti, J.P. (1993) Tissue Engineering. Science, 5110, 920-926. http://dx.doi.org/10.1126/science.8493529

[4] Temenoff, J.S. and Mikos, A.G. (2000) Review: Tissue Engineering for Regeneration of Articular Cartilage. Biomaterials, 5, 431-440. http://dx.doi.org/10.1016/S0142-9612(99)00213-6

[5] Ma, P.X., Zhang, R.Y., Xiao, G.Z. and Franceschi, R. (2001) Engineering New Bone Tissue in Vitro on Highly Porous Poly(alpha-hydroxyl Acids)/Hydroxyapatite Composite Scaffolds. Journal of Biomedical Materials Research, 2, $284-$ 293. http://dx.doi.org/10.1002/1097-4636(200102)54:2<284::AID-JBM16>3.0.CO;2-W

[6] Dalby, M.J., McCloy, D., Robertson, M., Wilkinson, C.D. and Oreffo, R.O. (2006) Osteoprogenitor Response to Defined Topographies with Nanoscale Depths. Biomaterials, 8, 1306-1315. http://dx.doi.org/10.1016/j.biomaterials.2005.08.028

[7] Oh, S., Brammer, K.S., Li, Y.S., Teng, D., Engler, A.J., Chien, S. and Jin, S. (2009) Stem Cell Fate Dictated Solely by Altered Nanotube Dimension. Proceedings of the National Academy of Sciences, 7, 2130-2135. http://dx.doi.org/10.1073/pnas.0813200106

[8] Lavenus, S., Berreur, M., Trichet, V., Pilet, P., Louarn, G. and Layrolle, P. (2011) Adhesion and Osteogenic Differentiation of Human Mesenchymal Stem Cells on Titanium Nanopores. European Cells and Materials, 96, 84-96.

[9] Karlsson, M., Palsgard, E., Wilshaw, P.R. and Di Silvio, L. (2003) Initial in Vitro Interaction of Osteoblasts with Nano-Porous Alumina. Biomaterials, 18, 3039-3046. http://dx.doi.org/10.1016/S0142-9612(03)00146-7

[10] La Flamme, K.E., Popat, K.C., Leoni, L., Markiewicz, E., La Tempa, T.J., Roman, B.B., Grimes, C.A. and Desai, T.A. (2007) Biocompatibility of Nanoporous Alumina Membranes for Immunoisolation. Biomaterials, 16, 2638-2645. http://dx.doi.org/10.1016/j.biomaterials.2007.02.010

[11] Gong, D.W., Yadavalli, V., Paulose, M., Pishko, M. and Grimes, C.A. (2003) Controlled Molecular Release Using Nanoporous Alumina Capsules. Biomedical Microdevices, 1, 75-80. http://dx.doi.org/10.1023/A:1024471618380

[12] La Flamme, K.E., Mor, G., Gong, D., La Tempa, T., Fusaro, V.A., Grimes, C.A. and Desai, T.A. (2005) Nanoporous Alumina Capsules for Cellular Macroencapsulation: Transport and Biocompatibility. Diabetes Technology \& Therapeutics, 5, 684-694. http://dx.doi.org/10.1089/dia.2005.7.684

[13] Gultepe, E., Nagesha, D., Sridhar, S. and Amiji, M. (2010) Nanoporous Inorganic Membranes or Coatings for Sustained Drug Delivery in Implantable Devices. Advanced Drug Delivery Reviews, 3, 305-315. http://dx.doi.org/10.1016/j.addr.2009.11.003

[14] Bruggemann, D. (2013) Nanoporous Aluminium Oxide Membranes as Cell Interfaces. Journal of Nanomaterials, 2013, $1-18$.

[15] Popat, K.C., Chatvanichkul, K.I., Barnes, G.L., Latempa, T.J., Grimes, C.A. and Desai, T.A. (2007) Osteogenic Differentiation of Marrow Stromal Cells Cultured on Nanoporous Alumina Surfaces. Journal of Biomedical Materials Research Part A, 4, 955-964. http://dx.doi.org/10.1002/jbm.a.31028

[16] Andersson, A.S., Backhed, F., von Euler, A., Richter-Dahlfors, A., Sutherland, D. and Kasemo, B. (2003) Nanoscale Features Influence Epithelial Cell Morphology and Cytokine Production. Biomaterials, 20, 3427-3436. http://dx.doi.org/10.1016/S0142-9612(03)00208-4

[17] Karlsson, M., Johansson, A., Tang, L. and Boman, M. (2004) Nanoporous Aluminum Oxide Affects Neutrophil Behaviour. Microscopy Research and Technique, 5, 259-265. http://dx.doi.org/10.1002/jemt.20040

[18] Hu, L.J., Lind, T., Sundqvist, A., Jacobson, A. and Melhus, K. (2010) Retinoic Acid Increases Proliferation of Human Osteoclast Progenitors and Inhibits RANKL-Stimulated Osteoclast Differentiation by Suppressing RANK. Plos One, 10, 2010.

[19] Dalby, M.J., Gadegaard, N., Tare, R., Andar, A., Riehle, M.O., Herzyk, P., Wilkinson, C.D.W. and Oreffo, R.O.C. (2007) The Control of Human Mesenchymal Cell Differentiation Using Nanoscale Symmetry and Disorder. Nature Materials, 12, 997-1003. http://dx.doi.org/10.1038/nmat2013

[20] Engler, A.J., Sen, S., Sweeney, H.L. and Discher, D.E. (2006) Matrix Elasticity Directs Stem Cell Lineage Specification. Cell, 4, 677-689. http://dx.doi.org/10.1016/j.cell.2006.06.044

[21] Dalby, M.J., Yarwood, S.J., Johnstone, H.J., Affrossman, S. and Riehle, M.O. (2002) Fibroblast Signaling Events in 
Response to Nanotopography: A Gene Array Study. IEEE Transactions on Nanobioscience, 1, 12-17. http://dx.doi.org/10.1109/TNB.2002.806930

[22] Ruhe, P.Q., Boerman, O.C., Russel, F.G.M., Mikos, A.G., Spauwen, P.H.M. and Jansen, J.A. (2006) In Vivo Release of rhBMP-2 Loaded Porous Calcium Phosphate Cement Pretreated with Albumin. Journal of Materials Science-Materials in Medicine, 10, 919-927. http://dx.doi.org/10.1007/s10856-006-0181-z

[23] Liu, Y., Huse, R.O., de Groot, K., Buser, D. and Hunziker, E.B. (2007) Delivery Mode and Efficacy of BMP-2 in Association with Implants. Journal of Dental Research, 1, 84-89. http://dx.doi.org/10.1177/154405910708600114

[24] Thies, R.S., Bauduy, M., Ashton, B.A., Kurtzberg, L., Wozney, J.M. and Rosen, V. (1992) Recombinant Human Bone Morphogenetic Protein-2 Induces Osteoblastic Differentiation in W-20-17 Stromal Cells. Endocrinology, 3, 1318-1324. http://dx.doi.org/10.1210/en.130.3.1318 